\title{
Analysis of the Status Quo and Thinking of Teachers' Information-based Teaching in Higher Medical education
}

\author{
Jianmei Ma ${ }^{1}$ Bibo $\mathrm{Liu}^{2} \mathrm{Fei} \mathrm{Li}^{3}$ Qian Yao ${ }^{4}$ Jing $\mathrm{Ni}^{5}$ \\ 1. Department of diagnostics, Clinical Medicial college, Xi'an Medical University, 710021; China; \\ 2. Department of surgery, Clinical Medicial college, Xi'an Medical University, 710021; China; \\ 3.Department of Pediatric Nursing, School of Nursing, Xi'an Medical University, 710021; China; \\ 4.Computer teaching and research section, department of health management ,710021; China; \\ 5.Department of diagnostics, Clinical Medicial college, Xi'an Medical University, 710021; China.
}

Keywords: higher medical education; information technology; current teaching situation; technology application.

\begin{abstract}
Changes have taken place in many fields with the development of computer information technology. In higher medical education, its application is conducive to improving teaching effectiveness and promoting the development of teaching.
\end{abstract}

\section{Introduction}

The teaching method has undergone great changes in the context of the rapid development of computer information. Since information technology can be applied into the entire process of teaching, the overall effect of teaching can be improved. However, it should be noted that, in the teaching of higher medical education, teachers still have some problems in the application of information technology that need to be solved. Solving these problems will help improve the application of information technology.

\section{Application Status of Information Technology in Current Medical Education}

\subsection{The Lack of Ideological Understanding in Information-Based Teaching}

The use of information can eliminate the defects in traditional teaching. It is necessary to promote the use of information technology in teaching and teachers also need to have awareness in this regard. However, some teachers have not been aware of the advantages of teaching informatization yet and are still skeptical. At the same time, medical colleges and universities do not lay stress on the construction of information in teaching management, which has affected the application of information technology. As a result, the development of teaching informatization has been constrained, restricting the achievement of teaching results.

\subsection{Insufficient Capital Expenditure in Information-Based Teaching}

Some medical colleges and universities have not fully implemented information-based teaching yet, mainly because there is not enough capital to invest in the infrastructure of information technology, which results in a lag in development. Due to differences in the level of economic development in various regions, there is an imbalance in the development of teaching informatization and some colleges have the problem of insufficient investment in informatization. Although some institutions have introduced advanced hardware equipment, a teaching platform has not been established in time due to technical constraints, which affects the information construction. In addition, in the implementation of teaching informatization, teaching resources are difficult to be shared because of limitations in the software platform, resulting in a waste of resources. 


\section{Principles of Teaching Design in the Context of Information Technology}

\subsection{Curriculum Standards Should Be Combined with Information Technology}

The curriculum standard is the principle on which the teaching should be based. Therefore, the integration of education informatization and education technology should be embodied in the curriculum standards. Clear curriculum standards are conducive to promoting the integration and also point out the goal and direction for the implementation of teaching reform. In this sense, the formulation of curriculum standards should fully consider the impact of education informatization on education. It is necessary to combine the characteristics of education informatization to improve the curriculum standards, so that they can play a guiding role in teaching.

\subsection{The Contents of Teaching Material Should Be Integrated with Information Technology}

Teaching is inseparable from teaching materials. In the context of information technology, the original textbooks are difficult to adapt to the requirements of education informatization due to the limitations of the contents, and thus they must be adjusted as necessary. The contents in existing textbooks should be improved in accordance with the characteristics of information-based teaching. Currently, information-based teaching methods represented by multimedia technologies have been used in teaching practice. However, the contents of teaching materials for many disciplines have not changed and the knowledge structure of these teaching materials still adopt the traditional model. They have not achieved the true integration with the information-based teaching method. Therefore, it is necessary to reform the curriculum contents based on the concept of integration and combine the characteristics of the students to develop teaching materials which can better meet the needs of integration.

\subsection{It is Needed to Realize the Combination of Information Technology Experts and Educational Experts}

The fusion of information technology and education is the integration of two disciplines. Therefore, in order to realize the effect of integration, information technology experts are expected to cooperate with education experts so as to enhance the effect of integration with a technology-joint approach. This can achieve effective integration of teachers, information technology and students as well as the close integration of teaching methods and information technology. With the participation of education experts, information-based teaching contents can better be integrated with teaching practice.

\section{The Application of Information Technology in Teaching}

\subsection{Improving Students' Learning Effectiveness}

Information technology can concretize concepts that are not easily understood, which can help students to conduct research and exploration. The ability improvement of students' divergent thinking and intuitive thinking is conducive to their learning of specialized courses. For example, in the analytic learning of pharmaceutical preparations, students must have a thorough understanding of various pharmaceutical preparations to ensure the quality of learning. In general, many details in drug preparations are not easily understood, but the interactive forms of learning can be realized if information technology is used. In the study of specialized courses, students can choose appropriate learning methods according to their actual situation, making the contents and time of study more flexible. Due to the richer teaching contents, students can use multimedia for self-study. They can detect the effect of learning immediately and this is helpful for them to find shortcomings and gaps in their learning. The use of multimedia can divide teaching contents into different levels according to the difficulty. Students can learn from easy to difficult step by step and gradually improve in a step-by-step manner, which is conducive to their mastery of knowledge. Information-based teaching can change the previous teaching mode. In general, in the teaching process of pharmaceutical preparations, teachers often explain contents following the planned chapters in the textbook and then summarize the knowledge points, so that students can gradually grasp the knowledge structure. Information-based teaching can change this form and make learning methods more flexible. In 
addition, the strong practicality of the specialty Medical Science has made the operational courses unable to be practiced completely in experiments due to the limitation of conditions. With the help of information-based teaching, the learning effect of experimental courses can be improved and the scope of learning can be expanded.

\subsection{Improving Students' Interest in Learning}

In the teaching practice of medical colleges, lots of knowledge can be mastered better only when it is combined with experiments. With the help of video, audio, animation and other forms of information-based multimedia teaching, teachers can visualize the analysis process of pharmaceutical preparations to facilitate students' understanding. For example, for phenomena such as water bath, evaporation and reflux, teachers can use information-based teaching to guide students to observe these phenomena and understand the correct methods of operation. Then they can give necessary guidance to let the students perform practical operations. This teaching method can guarantee the effect. This method also enables students to deeply understand the main points of the analysis of pharmaceutical preparations and enhance their interest in learning. The application of information-based teaching can animate the atmosphere of the classroom and change the way in the past that the teachers taught and students listened passively. This easy-to-accept teaching method has obvious advantages because it enables students to be active in thought and interested in information technology, which can enhance their initiative in learning. It allows students to complete their studies in a relaxed environment and enhance their interest in learning.

\subsection{Solving the Difficulties in Students' Learning}

Information technology is rich in information because it integrates a variety of media representations. Due to that it can demonstrate mathematical principles dynamically and visually, students can understand them easily, and therefore it can be used to break through the difficulties in teaching. Information technology can make the abstract theorem specific, which can effectively improve the effect of mathematics teaching. In previous teaching methods, teachers completed the explanation of teaching contents by means of chalk and blackboard. Students could only attend a lesson for one time. If they had difficulties or could not understand some contents, they had to ask the teacher again after class. Due to the influence of time, there was always a lag in solving difficulties. With multimedia information technology, students can learn courseware repeatedly. For those difficult contents, they can listen to the related lesson many times, which is helpful for them to understand better. In addition, many knowledge points of human anatomy require a comprehensive understanding and memory. It is difficult for teachers to explain these knowledge points only by chalk and blackboard, resulting in unsatisfactory teaching results. The application of multimedia technology makes it possible to sum up the contents of anatomy that cannot be described in words in the form of multimedia. By this way, the teaching contents become easier to be understood and this helps the students to understand the teaching content well.

\section{How to Apply Information Technology in the Teaching in Medical Colleges}

\subsection{To Create G a Teaching Environment}

The information-based teaching design needs the support of a corresponding teaching environment which is not only conducive to teachers' teaching but also beneficial to students' learning. Therefore, information-based teaching should attach importance to the scientific choices of software and software, and the informatization platform must meet the needs of teaching and learning. In the information-based teaching environment, teachers and students interact through terminal devices, and the establishment of a cloud platform enables the sharing of teaching resources. In such an environment, teachers and students can achieve effective and interactive communication. Furthermore, students can achieve individual learning and the mobile learning can meet their needs in various aspects.

\subsection{To Construct a Teaching Platform}

The realization of information-based teaching relies on a proper teaching platform. With the help of the teaching platform, teachers can complete various tasks, such as giving lessons, monitoring 
students' learning status, evaluating learning results, feeding back on learning status, and so on. In addition, the teaching platform can help realize the collection, sorting and transmission of teaching resources. Therefore, the design of the teaching platform has integrated functions and is easy to operate, which can reduce teachers' teaching burden and facilitate the implementation of information-based teaching. It can be seen as a new teaching tool for teachers. Due to the differences between disciplines, the teaching platform must have strong compatibility to meet the teaching needs of different disciplines.

\subsection{To Process Teaching Information}

In traditional teaching, teachers' evaluation of students' learning conditions is generally based on their teaching experience, leading to a certain degree of subjectivity. And in the case of a large number of students, the evaluation may not be scientific and reasonable. Information-based teaching can eliminate the defects existing in the traditional teaching. With special teaching software, teachers can completely record the information of students generated in the learning process. The recorded data can be classified and filtered, such as the student's preference of subject, the time they spend in the problem-solving process, the accuracy of a certain type of knowledge, etc. With these kinds of data, teachers can fully analyze students' learning status and help them adjust their teaching methods in a timely manner.

\subsection{To Integration Teaching Management and Information Technology}

In the implementation of teaching informatization, it is necessary to combine the key aspects of teaching to improve the informatization level of teaching management and enhance the management of lesson preparations, teaching, marking platforms, and so on. For example, the use of information technology can enrich the question bank of tests, achieving the combination of test questions and teaching. It is needed to build a platform for big data, develop and use databases related to exams, and use information technology to tap into potential information in the data to fully embody teaching functions. In addition, data and evaluation results about students must be used to provide the basis for teaching decisions, while data analysis should be used to implement feedback on teaching effectiveness at the same time.

\section{Paying Attention to Improving the Quality of Teachers}

\subsection{Capability of Software Operation}

Information-based teaching cannot be separated from the support of software. To achieve the integration of information-based teaching and education technology, teachers should master all kinds of teaching software. This is also the necessary ability for teachers to engage in teaching activities under the conditions of informatization. With the infiltration of information technology, teachers must not only be familiar with the use of various types of media tools but should also master the ways to make various types of electronic courseware, so that they can utilize a variety of information resources on the teaching platform. In this sense, the educational technology of teachers also needs to be improved.

\subsection{Capacity of Data Analysis}

Due to the involvement of information technology, teaching information becomes possible. In the teaching process, a large amount of data will be generated, including students' test results, learning ability, subject preference and many other aspects. Teachers need to have the capacity to analyze the data and can use data analysis software to mine potential information in the data. Based on the mined information, they can accurately grasp the students' learning status and combine the information to design teaching programs more scientifically and reasonably.

Teaching design capacity is an important part of educational technology and also a basic ability that teachers need to master in teaching. Especially in the context of information-based teaching, higher requirements are placed on teachers' teaching design capability. Teachers should improve their teaching design based on the characteristics of the disciplines and the information-based teaching. At the same time, the teaching design should fully consider the changes in students' learning styles under the informatization background and must strive to be precise. 


\section{Conclusion}

Great changes have taken place in the way of education under the background of the rapid development of information technology these days. The combination of teaching and information technology is the result of the current development of science and technology, which not only diversifies the teaching of schools but also facilitates teachers' preparations for lessons. Educators are expected to use information technology scientifically and reasonably to improve the quality of teaching. Teachers must actively study information technology and make it an advantageous tool for teaching. It is also necessary to combine the characteristics of education informatization, continuously promote the development of educational technology and give full play to the advantages of information technology, so as to enhance the effectiveness of education.

\section{Acknowledgments}

Excellent doctor education and training plan - pilot reform of five-year clinical medical talents training mode(No.[2012]20165).

\section{References}

[1]. Zhang Xiaowan, Feng Chunyu, Fan Xiumin. Study and Practice of the Teaching Mode "Theoretical Knowledge Learning Led by Practical Training" -- Taking the Course Pharmaceutical Preparation Technology as the Study Case [J]. Journal of Liaoning Agricultural College, 2016(2): 29-30.

[2]. Zhang Xiuling, Tian Junrong, Liu Zhongtao. Application of Multiple Teaching Method and Way in Pharmaceutical Technology [J]. China Medical Herald, 2017(1):36-37.

[3]. Liu Xiaohua. Application of Information Technology in Middle School Teaching in Guiyang [J]. Journal of Historical Education, 2016(4):42.

[4]. Miao Yingchun. Analysis of the Effectiveness of the Integration of Information Technology into Experiment Teaching and Its Implementation [J]. E-education Research, 2016(06)27-28.

[5]. Zhang Wenjun, Li Pingping. Why is information technology and education difficult to integrate with each other deeply [J] E-education Research, 2016 (11) : 123-124.

[6]. Zhang Tianli, Liu Hongwei. Teaching and Learning of Deep Integration of Information Technology and Education [J]. Continue Education Research, 2016(4): 108-109.

[7]. Guo Yanli. Intrinsic Factors in the Development of Information Technology Promoting the Success of Distance Education [J]. Continue Education Research, 2016(8): 56-57. 